\title{
AVALIAÇÃO DOS PARÂMETROS FÍSICO-QUÍMICOS DE FARINHAS DE RESIDUOS DO PROCESSAMENTO DE FRUTAS TROPICAIS
}

\author{
M. M. A. SOUSA ${ }^{1}$, D. N. SENA ${ }^{1}$, M. M. B. $\operatorname{ALMEIDA}^{2,}$ P. H. M SOUSA ${ }^{3}$, R. W. \\ FIGUEREDO $^{4}$, M. F. L. FERNANDES ${ }^{2}$ \\ ${ }^{1}$ Universidade Federal do Ceara, Departamento de Tecnologia de Alimentos \\ ${ }^{2}$ Universidade Federal do Ceara, Departamento de Química Analítica e Físico-Química \\ ${ }^{3}$ Universidade Federal do Ceara, Instituto de Cultura e Arte \\ ${ }^{4}$ Universidade Federal do Ceara, Departamento de Tecnologia de Alimentos \\ E-mail para contato: manuelaaguiar4@gmail.com
}

\begin{abstract}
RESUMO As determinações Físico-Químicas têm sido utilizadas para avaliar a composição química e nutricional dos alimentos e são importantes para manter o consumidor informado sobre tais parâmetros. Nesse trabalho foram analisados os teores de ácido ascórbico, acidez titulável, Sólidos Solúveis, Atividade de água (Aw) e $\mathrm{pH}$ em amostras de farinha proveniente de resíduos do processamento de acerola (Malpighia glabra), graviola (Annona muricata) e tangerina (Citrus reticulata). Os teores de ácido ascórbico e acidez foram analisados por métodos titulométricos, Sólidos Solúveis em refratômetro e $\mathrm{pH}$ em pHmêtro. As farinhas das frutas investigadas apresentaram altas concentrações de ácido ascórbico, valores superiores aos da IDR, podendo ser consideradas fonte importante desse nutriente As amostras apresentaram $\mathrm{pH}$ ácidos (3,55 e 4,56) Aw entre 0,35 e 0,41, o que tornam esses produtos de difícil contaminação microbiana. Foi verificado teor de acidez titulável de 1,08 a 1,67 g/100g e valores Sólidos Solúveis entre 17,15 - 33,81 ${ }^{\circ}$ Brix. Esses resultados abrem espaço para a possibilidade de utilização dos resíduos de acerola, graviola e tangerina como fonte alternativa de nutrientes, evitando o desperdício de alimentos.
\end{abstract}

\section{INTRODUÇÃO}

As regiões norte e nordeste brasileiras são reconhecidamente grandes produtoras de frutas tropicais, e com um maior número de pessoas aderindo a hábitos de vida saudável há um crescente aumento no consumo de frutas. Nesse setor além da demanda por frutas frescas, é crescente o mercado de sucos e polpas, por preservarem as características químicas e sensoriais da fruta fresca e por possibilitar ao consumidor encontrá-las durante o ano todo e devido a facilidade de consumo. Assim, como mostra o trabalho de Abud et al(2009), processamento dessas frutas gera cerca de $40 \%$ de resíduos agroindustriais, compostos de restos de polpa, casca, caroços ou sementes, o que mostra um crescente aumento do volume de lixo orgânico, provocando problemas ambientais, o que justifica a tentativa de aproveitamento desse tipo de resíduo. 
Além disso, estima-se que da área de produção até a mesa, cerca de 30 a $40 \%$ de produtos, como verduras, folhas e frutas, sejam jogados fora. Uma forma de reduzir o volume desse lixo é utilizar-se desses produtos para produção de farinhas de resíduos do processamento de frutas tropicais. Nesse contexto, estudos têm sido conduzidos com o intuito de investigar o valor nutricional desses resíduos, avaliando a sua utilização eficiente, econômica e segura no desenvolvimento de novos produtos alimentícios e aumentando seu valor agregado (SOUSA et al, 2011).

Concorda-se com alguns autores que defendem que, em um mundo globalizado, onde parte significativa da população encontra sérias dificuldades diariamente para conseguir alimento, é inconcebível que uma atividade agroindustrial continue desperdiçando um resíduo que potencialmente poderia ser utilizado como matéria-prima na indústria de alimentos (MORETTI; MACHADO, 2006).

Sabe-se ainda que, para a formulação das farinhas de resíduos pode-se utilizar de cascas, bagaço, sementes, e que as cascas são constituídas basicamente por carboidratos, proteínas e pectinas, o que possibilitaria seu aproveitamento para fabricação de doces, podendo-se tornar uma alternativa viável para resolver o problema da eliminação dos resíduos, além de aumentar seu valor comercial (MIGUEL et al, 2008).

Deve-se salientar que, os resíduos possuem um valor nutricional agregado. Surge, então, a necessidade de estudos visando o aproveitamento dos resíduos de processamento de frutas para a produção de alimentos que possam ser incorporados na alimentação humana, uma vez que as maiores quantidades de vitaminas e sais minerais de muitos alimentos se concentram nas cascas de frutas e legumes (ABUD et al,2009).

Assim, o presente trabalho teve por objetivo determinar os teores de ácido ascórbico, acidez, sólidos solúveis, Aw e pH em farinha proveniente de resíduos do processamento de amostras de tangerina, acerola e graviola, como forma de avaliar a qualidade e potencialidade da aplicação dessas farinhas em derivados alimentícios.

\section{METODOLOGIA}

Foram coletados resíduos do processamento de cedidos por indústrias produtora de polpa congelada de frutas de Fortaleza-CE. Da indústria, os resíduos foram transportados ao Laboratório de Frutas e Hortaliças da UFC, onde foram mantidos a $-18^{\circ} \mathrm{C}$. Depois de descongelados a temperatura ambiente, foram desidratadas em estufa de circulação forçada de ar a $65^{\circ} \mathrm{C}$, e em seguida triturados e peneirados. Os produtos em pó foram armazenados até a realização dos ensaios analíticos, em recipientes envoltos em papel alumínio e filme de PVC a temperatura ambiente.

O teor de umidade foi determinado de acordo como método descrito na Farmacopéia Brasileira (1988). Esse método baseia-se na perda de água por dessecação em estufa e visa determinar a quantidade de substância(s) volátil(eis) de qualquer natureza eliminada(s). As amostras foram separadas e mantidas a temperatura ambiente. Em seguida, suas massas ( $\sim \mathrm{g})$ foram pesadas em cadinhos cerâmicos, previamente dessecado durante 30 minutos, utilizando balança analítica modelo H54AR da marca Mettler. Esse procedimento foi realizado distribuindo o material de maneira uniformemente sobre o cadinho. Após a pesagem, o mesmo foi colocado em 
estufa à temperatura de $105{ }^{\circ} \mathrm{C}$ por 5 horas. Depois de arrefecidas à temperatura ambiente em dessecador, foram submetidas a nova pesagem até a obtenção do peso constante. Essas medidas foram realizadas em três repetições para cada amostra.

O teor de ácido ascórbico foi determinado pelo método Tillmans (titulométrico), que se baseia na redução de 2-6 - diclorofenol - indofenol (DCFI) pelo ácido ascórbico. O DCFI em meio básico ou neutro é azul, em meio ácido é rosa, e sua forma reduzida é incolor. O ponto final da titulação é detectado pela viragem da solução de incolor para rosa, quando a primeira gota de solução de DCFI é introduzida no sistema, com todo o ácido ascórbico já consumido. Os resultados foram expressos em mg de ácido ascórbico por $100 \mathrm{~g}$ de farinha.

Para a determinação da Acidez Titulável, tomou-se cerca de $1 \mathrm{~g}$ da amostra, a qual foi adicionada à $100 \mathrm{~mL}$ da agua destilada e agitada por 1 minuto. Essa solução foi titulada com solução de $\mathrm{NaOH}$ 0,1 mol.L $\mathrm{L}^{-1}$, usando fenolftaleína como indicador (BRASIL, Ministério da Saúde. Agência Nacional de Vigilância Sanitária, 2005)

As análises Sólidos Solúveis, determinados por refratometria, foram realizadas partindo-se de uma amostra de $10 \mathrm{~g}$ das farinhas alimentícios colocadas em um béquer e ai adicionado $100 \mathrm{ml}$ de água destilada e agitada por 30 minutos. Em seguida, colocou-se um pouco deste material em gaze e espremeram-se algumas gotas no refratômetro (marca ATAGO) fazendo-se a leitura direta no equipamento. O resultado obtido foi multiplicado pelo volume da diluição e corrigido para $20^{\circ}$, conforme as normas analítica de Brasil (2005)

A análise do $\mathrm{pH}$ foi realizada pesando-se $10 \mathrm{~g}$ da amostra em um erlenmeyer, onde foram acrescentados $100 \mathrm{~mL}$ da água a $25^{\circ} \mathrm{C}$. Essa solução foi agitada por $30 \mathrm{~min}$ e em seguida deixada em repouso por 10 minutos. Posteriormente, foi recolhido o sobrenadante e a leitura foi realizada em pHmêtro, previamente calibrado com tampão de pH 4,0 e 7,0, de acordo com as normas analíticas de Brasil para amostras sólidas.

Os valores de atividade de água (Aw) foram determinados através do medidor de Aw da marca Aqualab by decagon, modelo Pullmam, WA 99163.

\section{RESULTADOS E DISCUSSÃO}

Os parâmetros Físico-Químicos de farinhas de resíduos do processamento de frutas tropicais encontrados nesse trabalho estão apresentados na Tabela 1. Todas as análise foram realizadas em triplicata.

Tabela 1: Valores de Umidade, Ácido Ascórbico, Ácidez Titulável, pH, Aw e Sólidos Solúveis das farinhas proveniente de resíduos do processamento de acerola, graviola e tangerina.

\begin{tabular}{l|c|c|c}
\hline \multirow{2}{*}{ Parâmetros (em base seca) } & \multicolumn{3}{|c}{ Amostras } \\
\cline { 2 - 4 } & Acerola & Graviola & Tangerina \\
\hline Acidez Titulável(AT) $(\mathrm{g} / 100 \mathrm{~g})$ & $1,67 \pm 0,14$ & $1,08 \pm 0,05$ & $1,57 \pm 0,27$ \\
\hline Sólidos Solúveis Totais $(\mathrm{SST})\left({ }^{\circ}\right.$ Brix) & $33,81 \pm 2,29$ & $18,81 \pm 5,77$ & $17,15 \pm 3,54$ \\
\hline
\end{tabular}




\begin{tabular}{l|c|c|c}
\hline $\mathrm{Aw}$ & $0,41 \pm 0,06$ & $0,35 \pm 0,00$ & $0,51 \pm 0,00$ \\
\hline $\mathrm{pH}$ & $3,55 \pm 0,02$ & $4,42 \pm 0,04$ & $4,56 \pm 0,02$ \\
\hline Ácido. Ascórbico $(\mathrm{mg} / 100 \mathrm{~g})$ & $123,26 \pm 17,95$ & $83,96 \pm 5,90$ & $84,06 \pm 5,90$ \\
\hline
\end{tabular}

Os valores de sólidos solúveis totais variaram entre $17,15-33,81{ }^{\circ}$ Brix, para tangerina e acerola, respectivamente. Esses valores elevados eram previsíveis, tanto nos pós alimentícios obtidos das cascas quanto nos obtidos dos bagaços, uma vez que grande parte dos teores de sólidos solúveis totais presentes nas frutas, também estão presentes em seus resíduos. Os teores encontrados podem também ser justificados pela variação do processamento aplicado na extração da polpa, fatores climáticos, variedade do fruto, tipos de solo e diversos outros fatores agronômicos.

A acidez é um importante parâmetro na apreciação do estado de conservação de um produto alimentício. Os valores de acidez, encontrados nos pós dos resíduos de acerola, graviola e tangerina, variaram de 1,08/100g (graviola) a 1,67g/100g (acerola).

Os valores de $\mathrm{pH}$ encontrados variaram entre 3,55 (acerola) e 4,56 (tangerina), enquanto a atividade de agua (Aw) variou entre 0,41 (acerola) e 0,35 (graviola) (Tabela 1). Esses valores tornam os produtos alimentos de difícil contaminação microbiana, visto que apresentaram $\mathrm{pH}$ fora da faixa de pH ótimo para crescimento microbiana (que é entre 6,5 e 7,5) microbiano (LIMA et al, 2004) e Aw abaixo de 0,85 valor considerado limite, abaixo do qual não há crescimento de bactéria patogênicas e fungos (FRANCO, 2008). $\mathrm{O}$ pH encontrado para as farinhas de tangerina, graviola foi semelhante aqueles reportados por Uchoa e colaboradores (2008) para essas mesmas frutas e menores do que aquele valor encontrado Viana Júnior (2010) para a farinha de banana (UCHOA et al,2008). A Aw encontrada nesse estudo apresentaram valores concordantes com resultados reportados na literatura para farinha de frutas (UCHOA et al,2008).

Conforme a Tabela 1, pode-se verificar que, apesar de terem sido submetidos a secagem em estufa, as farinhas proveniente dos resíduos das amostras estudadas apresentam altas concentrações de ácido ascórbico. Ao compararmos com os valores de ingestão diária recomendada (IDR) que é de $60 \mathrm{mg}$ para adultos (BRASIL. Portaria SVS/MS no 33,1998), todos as amostras podem ser consideradas boas fontes de ácido ascórbico, pois fornecem de $139 \%$ (graviola) a 205\% (acerola) da IDR. A vitamina C é a mais facilmente degradável de todas as vitaminas, sendo estável apenas em meio ácido, na ausência de luz, de oxigênio e de calor. Provavelmente, o elevado teor desta vitamina, encontrado nas farinhas das frutas estudadas devase aos cuidados tomados no armazenamento dessas amostras.

Os resultados dessa investigação indicam ainda que, apesar de os resíduos terem de sofrido tratamento térmico, conseguem conservar ainda as características das frutas das quais eram provenientes.

\section{CONCLUSÃO}

Conclui-se com o presente trabalho que, as amostras estudadas apresentam valores significativos de ácido ascórbico, podendo ser consideradas fonte importante desse nutriente. As 
farinhas das frutas apresentam também altos valores de acidez, Aw baixa e pH ácidos, o que induz a que que as mesmas não alterem suas composições química inicial, nem sejam contaminadas por microrganismos, possibilitando assim o seu armazenadas por tempo significativo, em condições higiênicas.

Desta forma, os resultados para as farinhas das frutas analisadas abre espaço para a possibilidade da utilização dos resíduos de acerola, graviola e tangerina como fonte alternativa de nutrientes, evitando o desperdício de alimentos.

\section{REFERÊNCIAS}

ABUD, A. K. S.; NARAIN, N. Incorporação da farinha de resíduo do processamento de polpa de fruta em biscoitos: uma alternativa de combate ao desperdício. Brazilian Journal of Food Technology, v. 12, n. 4, p. 257-265, 2009.

BRASIL. Ministério da Saúde. Agência Nacional de Vigilância Sanitária. Métodos FísicoQuímicos para Análises de Alimentos. Diário Oficial da União Brasília: Ministério da Saúde, 2005. 1018p.

BRASIL. Portaria SVS/MS no 33, de 13 de janeiro de 1998. Tabelas de Ingestão Diária Recomendada (IDR). Diário Oficial da União, 16 jan. 1998.

FRANCO, B.D.G.M.; LANDGRAF, M. Microbiologia dos Alimentos. São Paulo: Editora Atheneu, 2008. 182p.

INSTITUTO ADOLFO LUTZ. Métodos Físico-Químicos para análise de alimentos. Coordenadores Odair Zenebon, Neus Sadocco Pascuet e Paulo Tiglea, $4^{\text {a }}$ Ed., São Paulo: Instituto Adolfo Lutz, 2008. p. 1020.

LIMA, AC, García NHP, Lima JR. Obtenção e caracterização dos principais produtos do caju. Boletim Ceppa. 2004; 22(1):133-144.

MIGUEL, A.C.A; ALBERTINI, S; BEGIATO, G, F; DIAS1, J.R.P.S; SPOTO, M.H.F; Aproveitamento agroindustrial de resíduos sólidos provenientes do melão minimamente processado, Ciênc. Tecnol. Aliment., Campinas, 28(3): 733-737, jul.-set. 2008.

MORETTI, C. M.; MACHADO, C. M. M. Aproveitamento de resíduos sólidos do processamento mínimo de frutas e hortaliças. 4, 2006, São Pedro. In: ENCONTRO NACIONAL SOBRE PROCESSAMENTO MÍNIMO DE FRUTAS E HORTALIÇAS. Palestras, Resumos, Fluxogramas e Oficinas... Piracicaba: USP/ESALQ, 2006. p. 25-32.

SOUSA, M. S. B.; VIEIRA, L. M.; SILVA, M. J. M., LIMA, A. Caracterização Nutricional e Compostos Antioxidantes em Resíduos de Polpas de Frutas Tropicais. Ciência e Agrotecnologia, v. 35, n. 3, p. 554-559, 2011. 
UCHÔA, A.M.A.; COSTA, J. M.C.; MAIA, G. A.; SILVA, E. M. C.; CARVALHO, A. F. F. U.; MEIRA, T. R. Parâmetros Físico-Químicos, Teor de Fibra Bruta e Alimentar de Pós Alimentícios Obtidos de Resíduos de Frutas Tropicais. Segurança Alimentar e Nutricional, v. 15, n.2, p. 58-65, 2008 .

VIANA JÚNIOR, N. M. Farinha de Banana madura - Processo de Produção e Aplicações. 2010, 57 f. (Mestrado em Engenharia de Alimentos) - Curso de Pós-Graduação em Engenharia de Alimentos, Universidade Estadual do Sudoeste da Bahia (UESB), Itapetinga 2010. 